\title{
Genetic mechanisms regulating the host response during mastitis
}

\author{
V. Asselstine, ${ }^{1}$ F. Miglior, ${ }^{1}$ A. Suárez-Vega, ${ }^{1}$ P. A. S. Fonseca, ${ }^{1}$ B. Mallard, ${ }^{2}$ N. Karrow, ${ }^{1}$ A. Islas-Trejo, ${ }^{3}$ \\ J. F. Medrano, ${ }^{3}$ and A. Cánovas ${ }^{1 *}$ \\ ${ }^{1}$ Centre for Genetic Improvement of Livestock, Department of Animal Biosciences, University of Guelph, Guelph, Ontario, Canada, N1G 2W1 \\ ${ }^{2}$ Department of Pathobiology, Ontario Veterinary College, University of Guelph, Guelph, Ontario, Canada, N1G 2W1 \\ ${ }^{3}$ Department of Animal Science, University of California-Davis, Davis 95616
}

\section{ABSTRACT}

Mastitis is a very costly and common disease in the dairy industry. The study of the transcriptome from healthy and mastitic milk somatic cell samples using RNA-Sequencing technology can provide measurements of transcript levels associated with the immune response to the infection. The objective of this study was to characterize the Holstein milk somatic cell transcriptome from 6 cows to determine host response to intramammary infections. RNA-Sequencing was performed on 2 samples from each cow from 2 separate quarters, one classified as healthy $(\mathrm{n}=6)$ and one as mastitic $(\mathrm{n}=6)$. In total, 449 genes were differentially expressed between the healthy and mastitic quarters (false discovery rate $<0.05$, fold change $> \pm 2$ ). Among the differentially expressed genes, the most expressed genes based on reads per kilobase per million mapped reads (RPKM) in the healthy group were associated with milk components (CSN2 and CSN3), and in the mastitic group they were associated with immunity (B2M and CD74). In silico functional analysis was performed using the list of 449 differentially expressed genes, which identified 36 significantly enriched metabolic pathways (false discovery rate $<0.01$ ), some of which were associated with the immune system, such as cytokine-cytokine interaction and cell adhesion molecules. Seven functional candidate genes were selected, based on the criteria of being highly differentially expressed between healthy and mastitic groups and significantly enriched in metabolic pathways that are relevant to the inflammatory process (GLYCAM1, B2M, CD\%4, BoLA-DRA, FCER1G, SDS, and NFK$B I A)$. Last, we identified the differentially expressed genes that are located in quantitative trait locus regions previously known to be associated with mastitis, specifically clinical mastitis, somatic cell count, and somatic cell score. It was concluded that multiple genes

Received February 16, 2019.

Accepted June 5, 2019.

*Corresponding author: acanovas@uoguelph.ca within quantitative trait locus regions could potentially affect host response to mastitis-causing agents, making some cows more susceptible to intramammary infections. The identification of potential candidate genes with functional, statistical, biological, and positional relevance associated with host defense to infection will contribute to a better understanding of the underlying genetic architecture associated with mastitis. This in turn will improve the sustainability of agricultural practices by facilitating the selection of cows with improved host defense leading to increased resistance to mastitis.

Key words: mastitis, milk somatic cell, RNASequencing, dairy cattle

\section{INTRODUCTION}

Mastitis is one of the most challenging and profitlimiting diseases in lactating dairy cows. Mastitis, or rather, inflammation of the udder, is caused by bacterial pathogens that enter the udder and trigger an immune response (Martin et al., 2018). There are 2 types of mastitis: clinical mastitis ( $\mathbf{C M})$, which is detected by abnormalities in the milk and inflammation in the udder, and subclinical mastitis (SCM), which is more challenging to diagnose because of a lack of clinical signs (Santman-Berends et al., 2012). Antibiotics may be used to treat mastitis cases, but there is an increase in pressure to reduce the amount of antibiotics used in food animals (Godden et al., 2017). Therefore, producers need better ways to treat and prevent mastitis to maintain the health of their herd. One way this can be achieved is by focusing on natural defense mechanisms the cow has to protect against IMI. One of these mechanisms is the formation of the mucus layer in the teat, which forms after milking. This mucus layer is highly hydrated and acts as a natural physical barrier that can prevent bacteria from entering the mammary gland. The faster this plug forms, the fewer bacteria can enter the canal (Corfield, 2015). Within this mucus layer are mucins that aid in the host's immune response by trapping pathogens (Dhanisha et al., 2018). How- 
ever, some cows are able to form this mucus plug more efficiently, thus, there is interest in monitoring the host response to IMI in the context of mucin plug formation.

During mastitis cases, increasing somatic cells (SC) are used as an important indicator of udder health, as certain SC are part of the innate immune system due to their role in protecting the mammary gland from infection (Li et al., 2014). Somatic cells, which consist of macrophages, PMN, lymphocytes, and epithelial cells (Li et al., 2014), are naturally present in milk, although the composition varies depending on the health status of the udder quarter. In the healthy udder quarter, relatively low numbers of mammary epithelial cells are shed into the milk and represent a proportion of the SC found in milk. However, macrophages are also present, which are the predominant cell type found in healthy cow milk, as they quickly fight bacterial invasion (Cánovas et al., 2014a; Li et al., 2014). In the mastitic quarter, macrophages release chemical messengers to direct PMN toward the infection site, which increases milk SCC. Once the PMN arrive, they phagocyte the microorganisms and kill them, and have been shown to be in quantities as high as $92 \%$ in mastitic milk (Paape et al., 1979; Pham, 2006; Li et al., 2014). Consequently, as the cell populations differ during infection, SC gene expression will also differ. Therefore, it is worth investigating the transcriptome of the milk SC in the healthy and mastitic quarters, to determine genes that are differentially expressed (DE) between the 2 quarters.

The objectives of this study were (1) to identify milk SC genes DE between healthy and mastitic samples using RNA-Sequencing (RNA-Seq); (2) to perform functional analysis to identify the biological processes, molecular functions, and metabolic pathways using the list of DE genes; (3) to integrate transcriptomic and functional data to identify functional candidate genes involved in host immune response and mucin development; and (4) to identify positional and functional candidate genes among the DE genes located within QTL regions previously associated with mastitis, specifically, CM, SCC, and SCS. The findings from this study will provide a better understanding of host immune response to mastitis and the genetic mechanism of mucus plug formation in the mammary gland, specifically looking at the formation of mucins.

\section{MATERIALS AND METHODS}

\section{Animal and Sample Collection}

Six Holstein dairy cows ranging from first to third and later lactations were used in this study (Supplemental Table S1; https://doi.org/10.3168/jds.2019 -16504). The animals were housed in a freestall dairy facility at the University of California-Davis, fed a TMR, and supplied water ad libitum. All protocols used were approved by the University of CaliforniaDavis Institutional Animal Care and Use Committee. The California Mastitis Test was used to detect the early presence of mastitic inflammation without visible abnormalities in the milk (Guerrero et al., 2015; Godden et al., 2017). This study looked at natural cases of mastitis, and therefore, as soon as a cow was diagnosed with mastitis according to the California Mastitis Test, milk samples were collected as described by Guerrero et al. (2015). Two different samples were taken from each cow immediately after diagnosis, one sample from the mastitic quarter $(n=6)$, and the other sample taken diagonally across from the mastitic quarter, which was confirmed as the healthy quarter $(\mathrm{n}=6)$, based on having a SCC $<100,000$ cells/mL (Guerrero et al., 2015). Using examination gloves, the cow's teat was cleaned with gauze and damped in 70\% isopropanol and $50-\mathrm{mL}$ milk samples were collected using a 3 -cm plastic cannula (Genesis Industries Inc., Elmwood, WI) to ensure no external bacteria contaminated the sample. Milk was kept on ice and immediately processed for RNA extraction.

\section{RNA Extraction}

As described by Cánovas et al. (2010) samples were centrifuged at $2,000 \times \mathrm{g}$ for $10 \mathrm{~min}$ at $4^{\circ} \mathrm{C}$ to pellet $\mathrm{SC}$ and to separate the upper milk fat globule fraction. After the fat was removed, the milk was decanted from the tube and the pelleted SC were washed by resuspending them in $10 \mathrm{~mL}$ of RNase-free PBS at $\mathrm{pH}$ 7.2 , followed by centrifugation at $2,000 \times g$ at $7^{\circ} \mathrm{C}$ for 10 min. The supernatant was decanted, and the milk pellet was resuspended with $1 \mathrm{~mL}$ of Trizol (Invitrogen, Grand Island, NY). Total RNA was purified following the Trizol protocol (Invitrogen, Carlsbad, CA), and the RNA was quantified by an ND-1000 Nanodrop Spectrometer (Thermo Scientific, Pittsburgh, PA; Cánovas et al., 2013). Quality was evaluated using the RNA integrity number value from the Experion automated electrophoresis system (Bio-Rad, Hercules, CA; Cánovas et al., 2013). The RNA integrity number values ranged from 8.0 to 9.0 in all milk SC samples, indicating good RNA quality (Cánovas et al., 2013).

\section{Library Construction and RNA-Seq Analysis}

Library construction was performed using the TruSeq RNA sample preparation kit (Illumina, San Diego, CA; Cánovas et al., 2014b). Adapters were ligated to the ends of double-stranded cDNA and PCR amplified to create libraries. Sequencing was completed with an Il- 
lumina HiSeq 2000 analyzer that yielded 100-bp single read sequences. Sequence reads were assembled to the annotated UMD3.1 bovine reference genome (Ensembl release 90) using the CLC genomics workbench software (CLC Bio, Aarhus, Denmark). Quality control analysis was performed using the NGS quality control tool of CLC Genomics workbench software (version 10.0). Quality control analysis included GC content, ambiguous base content, Phred score, base coverage, nucleotide contributions, and over-represented sequence parameters (Cánovas et al., 2014a). All samples passed the quality control analysis showing same length (100 bp), $100 \%$ coverage in all bases, $25 \%$ of A, T, G, and $\mathrm{C}$ nucleotide contributions, $50 \% \mathrm{GC}$ base content, and less than $0.1 \%$ over-represented sequences (Cánovas et al., 2014a). Transcript levels were quantified in reads per kilobase per million mapped reads (RPKM). By normalizing the data for RNA length and total reads in each sample, the RPKM measure facilitated comparisons of transcript levels between both groups (Mortazavi et al., 2008). Previous research by Wickramasinghe et al. $(2012,2014)$ revealed a threshold value 0.2 RPKM for detectable gene expression in milk SC. Differential gene expression analysis was performed between healthy $(\mathrm{n}=6)$ and mastitic $(\mathrm{n}=6)$ quarters by $t$-test (CLC Bio). We considered genes to be DE between healthy and mastitic quarters when they had a $P$-value $<0.01$, a false discovery rate $(\mathbf{F D R})$ of $\mathrm{q}$ $<0.05$, and a fold-change $(\mathbf{F C})> \pm 2$. Associated gene name annotation was performed using the Ensembl biomart tool (http://useast.ensembl.org/index.html). In addition, the RPKM expression values of the DE genes were assigned to 3 categories as described by Wickramasinghe et al. (2012) to compare between high, medium, and low differential gene expression in healthy and mastitic groups: high expression ( $\geq 500$ RPKM), medium expression $(\geq 10$ to $500 \mathrm{RPKM})$, and low expression $(<10 \mathrm{RPKM})$.

\section{In Silico Functional Analysis}

Functional analysis including gene ontology (GO) enrichment analysis and metabolic pathway analysis were performed using the list of DE genes by Panther software (Thomas et al., 2003), using the bovine UMD3.1 reference genome as the reference set. The GO terms associated with the 3 main GO categories (biological processes, molecular function, and cellular component) were analyzed. Cluster dendrogram and heatmap analysis were performed to identify the hierarchical clustering of the global gene expression (transcriptome) between healthy and mastitic quarters using a custom script, with a distance matrix calculated using the Manhattan method in $\mathrm{R}$ software (version 3.2.3). Metabolic path- way enrichment analysis was performed using the Bioconductor package Kyoto Encyclopedia of Genes and Genomes (KEGG) profile package (Zhao et al., 2012a) in R. A threshold of FDR $<0.05$ was used to obtain highly significant metabolic pathways. Gene network analysis was performed on the unique genes involved in the significant metabolic pathways associated with immune response using STRING (Szklarczyk et al., 2017; https://string-db.org). The STRING database is used to perform analysis to visualize through gene networks the protein-protein interactions (PPI) in a list of genes (Szklarczyk et al., 2017). A list of 102 unique DE genes involved in the immune system related pathways was used to perform the gene network analysis specifically for the Bos taurus organism with default parameters. Once the network was created, we filtered the network to keep those genes showing a minimum PPI score of 0.7 (high confidence PPI score). Protein-protein interaction score refers to the approximate probability that a predicted connection exists between 2 enzymes in the same metabolic map in KEGG database (Szklarczyk et al., 2017). In addition, the STRING software completed a functional enrichment analysis on the genes used to construct the network, in which the enriched KEGG pathways within the network were identified. Additional gene network analysis was also performed using both the gene names and expression values (FC) using NetworkAnalyst software (http://www.networkanalyst .ca). Using NetworkAnalyst software, a tissue-specific PPI network analysis was performed using breast mammary tissue as the target tissue. The option "Minimum Network" was used in NetworkAnalyst to construct a minimally connected network that contains all of the genes (seeds) uploaded for the analysis. This means that the software adds the minimum number of additional genes to connect the disjointed networks created with the seeds. Then a KEGG enrichment analysis was performed using the upregulated nodes and the downregulated nodes separately. Lastly, integrating transcriptomic and functional data using a Venn diagram identified functional candidate genes based on overlapping different criteria: (1) DE genes, (2) highly $\mathrm{DE}$ genes with RPKM $\geq 500$, and (3) genes involved in significant metabolic pathways.

\section{Filtering Genes in QTL Regions Related to Mastitis}

The coordinates of the regions containing QTL relating to mastitis, specifically, CM, SCC, and SCS were downloaded from the cattle QTL database (release 35; $\mathrm{Hu}$ et al., 2016; https://www.animalgenome.org/cgi -bin/QTLdb/BT/index; CattleQTLdb, 2018). Once the files for CM, SCS, and SCC were downloaded, the files were prepared according to chromosome number, 


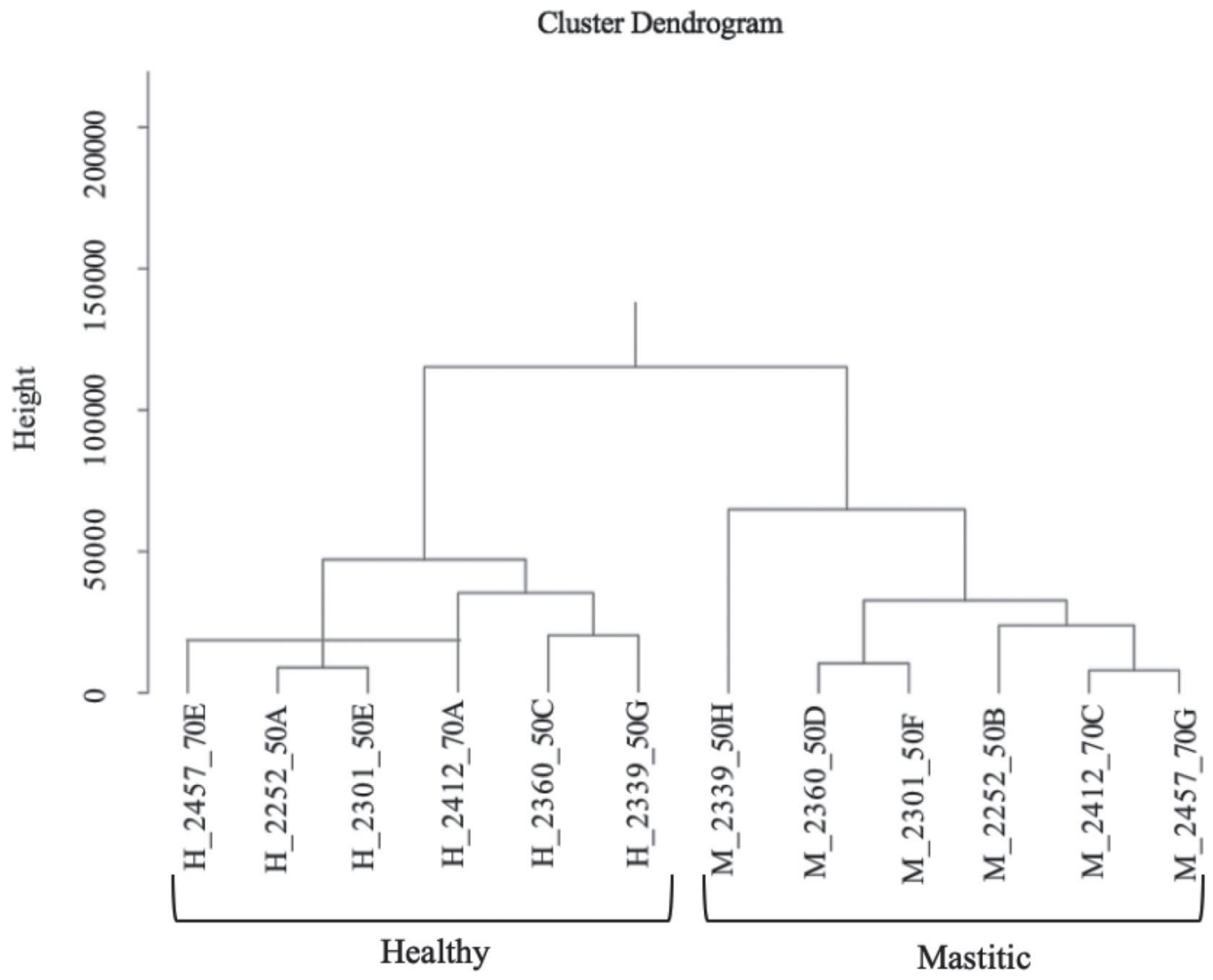

Figure 1. Cluster dendrogram of the milk somatic cell transcriptome analyzed from healthy $(\mathrm{n}=6)$ and mastitic $(\mathrm{n}=6)$ groups.

chromosome start, chromosome end, and saved as a bed file to be used in BEDTools (Quinlan and Hall, 2010). The BEDTools script was used to intersect the regions of the DE genes with the regions of the reported QTL, and the information was extracted to identify QTL related to $\mathrm{CM}$, SCC, and SCS.

\section{RESULTS AND DISCUSSION}

\section{Summary Statistics of the RNA-Seq Analysis}

In total, 226 million reads were generated from milk SC samples $(\mathrm{n}=12)$ using RNA-Seq. On average, each of the 12 samples generated $\sim 19$ million reads (Supplemental Table S2; https://doi.org/10.3168/jds.2019 -16504). The RNA-Seq analysis revealed that $\sim 78 \%$ of the reads were mapped to the annotated UMD3.1 bovine reference genome (release 90; 26,740 genes). The total number of genes expressed in healthy and mastitic groups were 13,322 and 15,126 , respectively (RPKM $\geq 0.2)$. Last, all samples clustered perfectly between healthy and mastitic quarters as illustrated in the cluster dendrogram (Figure 1) and the heat map (Figure 2). The data discussed in this publication have been deposited in NCBI's Gene Expression Omnibus and are accessible through Gene Expression Omnibus series accession number GSE131607 (https://www.ncbi .nlm.nih.gov/geo/query/acc.cgi?acc = GSE131607).

\section{DE Genes Between Healthy and Mastitic Groups}

Differential gene expression analysis between healthy and mastitic groups was performed identifying $449 \mathrm{DE}$ genes $(P<0.01, \mathrm{FDR}<0.05$, and $\mathrm{FC}> \pm 2)$. When comparing the healthy to mastitic group, of the $449 \mathrm{DE}$ genes, 200 were underexpressed in the mastitic group and 249 genes were overexpressed in the mastitic group based on their FC values. The most underexpressed $(\mathrm{FC}=-84.28)$ gene in the mastitic group was solute carrier family 34, member 2 (SLC34A2). In a recent study analyzing putative biomarkers for disease in bovine milk, it was found that the SLC34A2 gene encodes a sodium-dependent phosphate transporter, and this gene was upregulated in highly resistant cows (van Altena et al., 2016). Alternatively, the serum amyloid A protein $(S A A)$ gene was the most overexpressed (FC $=117.89)$ gene in the mastitic group. As mastitis is inflammation and the product of $S A A$ is a marker of 

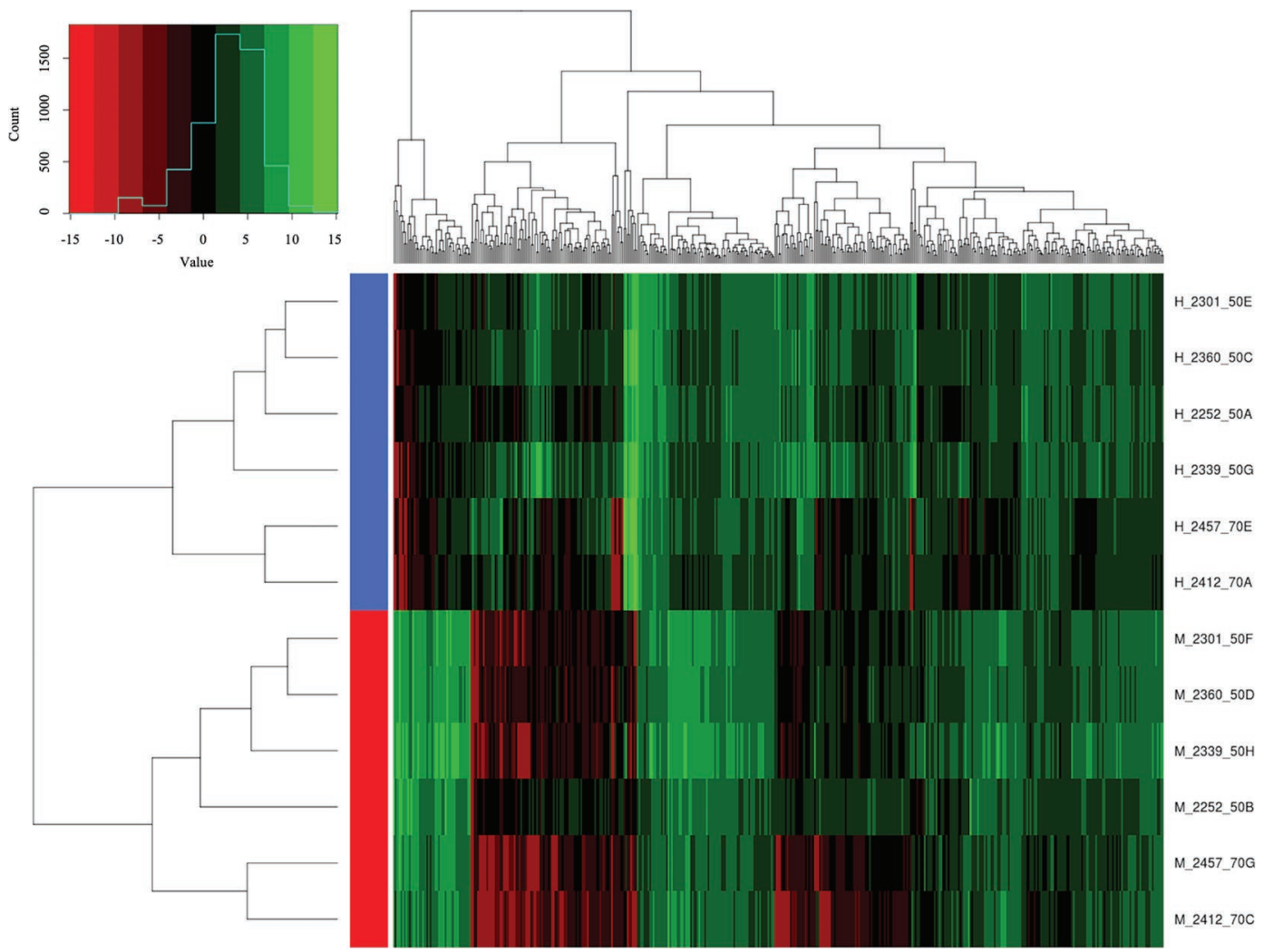

Figure 2. Heatmap showing the hierarchical clustering for the global gene expression differences between healthy and mastitic groups. The vertical and horizontal dendrograms correspond to the sample and gene hierarchical clustering, respectively. The vertical blue bars represent the healthy samples $(n=6)$, and the vertical red bars represent the mastitic samples $(n=6)$. The expression values are shown in $\log _{2}(\mathrm{RPKM})$ scale. Green shades represent high expression, and red shades represent low expression. RPKM = reads per kilobase per million mapped reads.

inflammation, shown to be expressed at different levels based on inflammatory stimuli (Chami et al., 2015), this result could be expected. Research by Gerardi et al. (2009) aimed to validate $S A A$ as an indicator for mastitis; however, they found that $S A A$ concentration was not useful to discriminate between CM or SCM. Moreover, other studies have shown that healthy cows have very low levels of $S A A$, such as Nielsen et al. (2004) who found significantly higher levels of $S A A$ in cows with mastitis compared with healthy cows $(P$ value $<0.05)$. This is in concordance with the results found in the current study as the gene expression values for the mastitic group was 46.99 RPKM, whereas in the healthy group it was 0.30 RPKM.

\section{GO Enrichment Analysis}

The 3 main GO categories (biological process, molecular function, and cellular component) were analyzed using the list of $449 \mathrm{DE}$ genes. A total of 549, 392, and 317 significantly enriched GO terms were identified in the biological process, molecular function, and cellular component GO categories, respectively. Fourteen biological processes were found including biological adhesion and response to stimulus; however, the main GO terms associated with the biological processes were cellular processes and biological regulation (Figure 3a). Regarding molecular functions, 7 GO terms were found, but the main GO terms were catalytic activity and binding activity (Figure 3b). Last, the main GO term for cellular processes were cell part and organelle; however, in total there were $7 \mathrm{GO}$ terms (Figure 3c). The results obtained are similar to a study by Yang et al. (2014) who investigated N-linked glycosylated proteins of mammary gland tissue from healthy and mastitic cows. The genes from their study were present in 10 biological processes that were the same as 9 of ours, whereas only some of the molecular function and cellular component categories were the same (Yang et al., 2014). In the present study we evaluated the alternative transcript profile between mastitic and healthy samples. Among these genes, the most common GO terms mentioned above are in concordance with results obtained across species such as human, mouse, and swine (Kroll et al., 2015; Cardoso et al., 2018). In general, genes expressing alternative transcripts are as- 


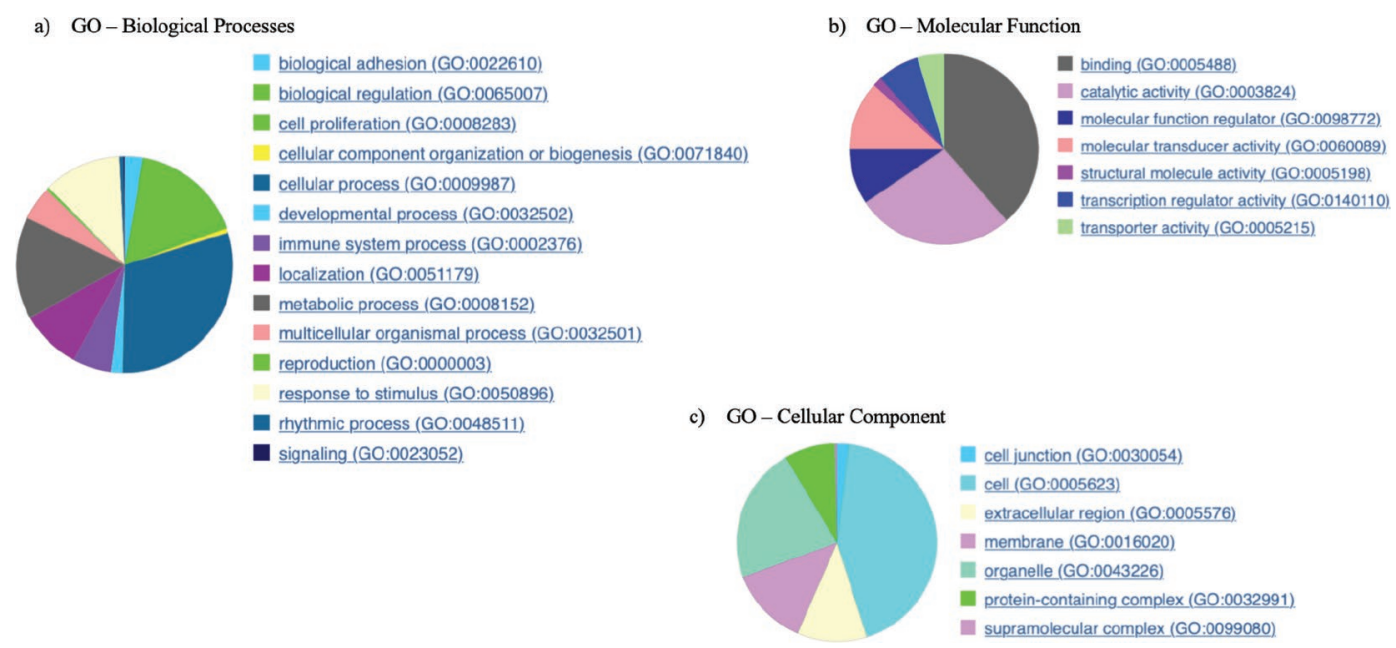

Figure 3. Associated Gene Ontology (GO) terms with differentially expressed genes in healthy and mastitic samples $(P$-value $<0.01$, false discovery rate $<0.05$, fold change $> \pm 2$ ) in the GO categories (a) biological process, (b) molecular function, and (c) cellular component.

sociated with heterogeneous role in biological functions, which can be the cause of the unspecific profile for GO terms that were identified in our study (Cardoso et al., 2018).

\section{High, Medium, and Low DE Genes in the Healthy and Mastitic Groups}

To compare expression levels of the DE genes between the healthy and mastitic groups, the RPKM expression values of the $\mathrm{DE}$ genes were assigned to 3 categories high ( $\geq 500$ RPKM), medium ( $\geq 10$ to 500 RPKM), and low (<10 RPKM) expressed genes (Wickramasinghe et al., 2012). As presented in Table 1, in the healthy group, 10 genes were highly DE (RPKM ranged from 503.16 to 10,808.45), 264 genes were medium DE (RPKM ranged from 10.01 to 322.24 ), and 175 genes had low DE values (RPKM ranged from 0.23 to 9.97). The highest expressed genes in the healthy group were $\beta$-casein (CSN2), $\kappa$-casein (CSN3), $\alpha_{\mathrm{S}_{1} \text {-casein }}$ $(C S N 1 S 1), \beta-\mathrm{LG}(B L G)$, and $\alpha_{S_{2}}$-casein (CSN1S2; Table 2). $\beta$-Casein, along with whey, are the 2 major protein groups found in bovine milk (Kamiñski et al., 2007). Approximately $80 \%$ of the proteins in bovine milk consist of caseins (Coulon et al., 1998). Within the casein category, 4 different caseins are expressed in milk: CSN2 (25 to $35 \%$ of caseins in milk), CSN1S1 (39 to $46 \%$ ), CSN1S2 (8 to $11 \%$ ), and CSN3 (8 to 15\%; Eigel et al., 1984; Roginski, 2003). Although CSN1S1 and CSN2 were not the most expressed in the mastitic group, they were still highly expressed with expression values of 672.83 and 638.28 RPKM, respectively. However, in comparison to the healthy group, these expression values were much lower (Table 2). The $B L G$ was highly expressed in the healthy group, and is one of the major whey proteins of ruminant species, and along with $\alpha-\mathrm{LG}$, contributes approximately $14 \%$ of the protein in milk (Coulon et al., 1998; Kontopidis et al., 2004; Kamiñski et al., 2007). In the mastitic group, both $B L G$ and $C S N 3$ were not in the highly expressed group. A possible implication for the lower expression levels of these genes is that the protein content in mastitic cow milk would decrease, which would have an economic implication. This is supported by Heringstad et al. (2005) who found an antagonistic genetic relationship between CM and protein yield. Similarly, protein and fat percentages are positively correlated (0.67), which means that if the protein percent in milk is decreasing, fat percent will also decrease, resulting in a greater implication for the profitability of cow milk (Carlén et al., 2004). Hogarth et al. (2004) also found that the milk proteome changes with mastitis and contains lower concentrations of caseins, $\alpha-L A$, and $\beta$-LG. It is also possible that these genes were not highly expressed due to an increased proportion of inflammatory cells in the mastitic milk SC samples compared with the nonmastitic ones.

In the mastitic group, 12 genes were highly expressed (RPKM ranged from 521.17 to 2,707.40), 241 genes were medium expressed (RPKM ranged from 10.53 to 490.53), whereas 196 genes had a low expression value (RPKM ranged from 0.20 to 9.62 ). The highest DE expressed genes in the mastitic group were $\beta-2-$ microglobulin (B2M), CD74 molecule $(C D \% 4)$, major histocompatibility complex class II DR $\alpha(B o L A-D R A)$, serine dehydratase $(S D S)$, and L-lactate dehydrogenase A chain ( $L D H A$; Table 2$)$. When an inflammatory process involving cell damage occurs, $L D H$ is released from 
Table 1. Average number of genes with high, medium, and low expression values, as well as reads per kilobase per million mapped reads (RPKM) values for each health group ${ }^{1}$

\begin{tabular}{lcc}
\hline Category & $\begin{array}{c}\text { Average } \\
\text { healthy } \\
\text { genes (no.) }\end{array}$ & $\begin{array}{c}\text { Average } \\
\text { mastitic } \\
\text { genes (no.) }\end{array}$ \\
\hline High expressed $^{\text {iii }}$ & 10 & 12 \\
Medium expressed $^{\text {ii }}$ & 264 & 241 \\
Low expressed & 175 & 196 \\
RPKM $\geq 0.2$ & 447 & 447 \\
RPKM $\leq 0.2$ & 2 & 2 \\
\hline
\end{tabular}

${ }^{1} \mathrm{i}=<10$ RPKM; ii $=\geq 10$ to 500 RPKM; iii $=\geq 500$ RPKM.

cells into the milk (Jørgensen et al., 2016); therefore, $L D H$ activity increases with mastitis (Bogin et al., 1977; Harmon, 1994). This evidence supports the high expression values of $L D H A$ gene in the SC milk samples from mastitic quarters. Three genes $(B 2 M, C D \% 4$, and $B o L A-D R A)$ are directly related to the major histocompatibility complex (MHC) molecules, which are a fundamental part of the immune system that facilitate antigen recognition, presentation, and activation of an acquired immune response (Behl et al., 2012). In bovine species, this MHC is referred to as bovine leukocyte antigens (BoLA), and polymorphisms in the BoLA-DR genes have been associated with resistance to infectious diseases such as mastitis (Rupp et al., 2007; Baltian et al., 2012). Both CD74 and BoLA-DRA are involved with antigen presenting cells (APC), which aid in the protection of the host as they signal CD4+ T helper cells, which kill the pathogen as part of the immune response. The presence of 2 highly expressed genes that are involved with APC is a notable finding because, as previously discussed, the major SC in early infection are PMN, which are released in large quantities when pathogens affect the mammary gland. It would be expected that there would be more genes directly related to PMN rather than APC. However, as discussed by Whale et al. (2006), PMN can display MHC and act as APC. In the mastitic group, it is clear that the immune system was focusing on fighting the infection in the mammary gland rather than being an efficient milk producer, which has economic implications for the producer.

\section{Functional Analysis: Metabolic Pathway Analysis and Gene Networks Involved in Immune Response}

Metabolic pathway enrichment analysis was performed using KEGGprofile package identifying 36 metabolic pathways significantly over-represented among the DE genes (FDR <0.01; Table 3$)$. Of these 36 pathways obtained, we looked further into the significant metabolic pathways that are involved with the host immune response. This identified 11 significant metabolic pathways that play a key functional role in the host's immune response. Within these 11 metabolic pathways, it was found that 102 unique DE genes were present. Two PPI network analysis were performed with the unique genes found in these immune pathways using

Table 2. Differentially expressed genes classified as highly expressed in the healthy and mastitic groups

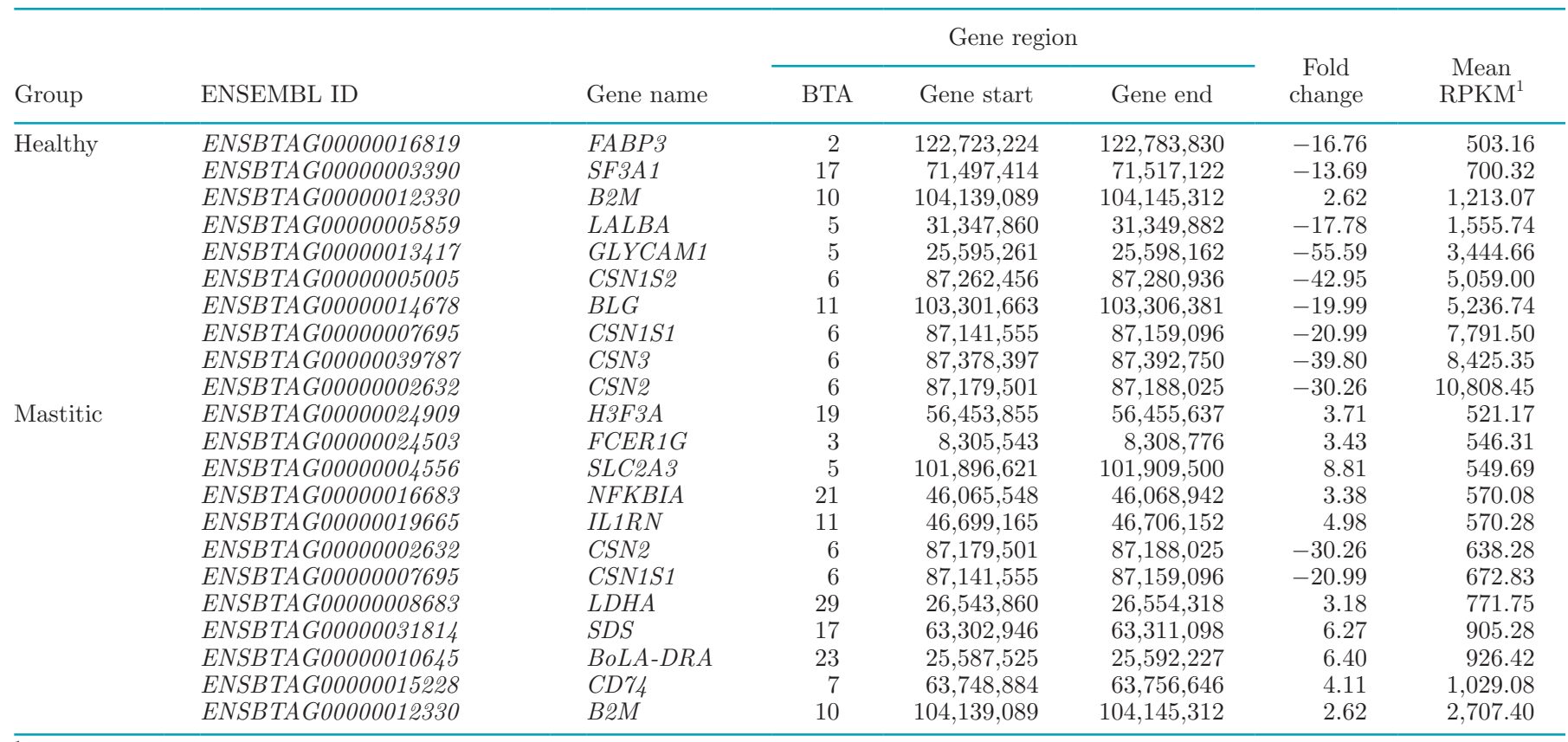

\footnotetext{
${ }^{1} \mathrm{RPKM}=$ reads per kilobase per million mapped reads.
} 
Table 3. Significant Kyoto Encyclopedia of Genes and Genomes metabolic pathways (false discovery rate $<0.01$ ) associated with the differentially expressed (DE) genes

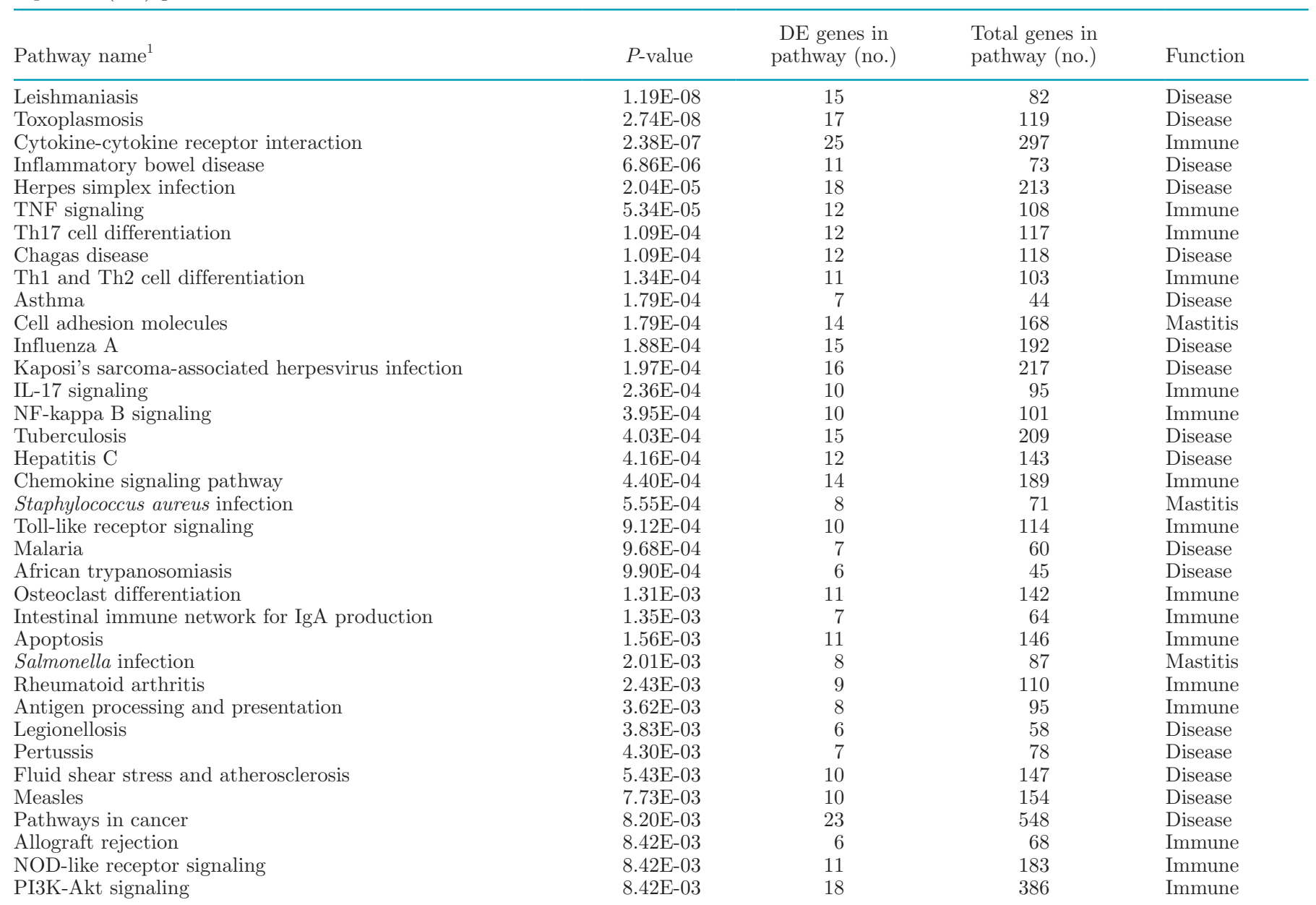

${ }^{1} \mathrm{TNF}=$ tumor necrosis factor; $\mathrm{Th}=\mathrm{T}$ helper; $\mathrm{NF}=$ nuclear factor; $\mathrm{NOD}=$ nucleotide binding and oligomerization domain; $\mathrm{PI} 3 \mathrm{~K}-\mathrm{Akt}=$ phosphoinositide-3-kinase-protein kinase B.

STRING and NetworkAnalyst. Both software perform gene network analysis; however, STRING predicts PPI among the gene list uploaded into the software $\mathrm{Sz}^{-}$ klarczyk et al., 2017; https://string-db.org), whereas NetworkAnalyst constructs the network including external genes to connect all the candidate genes and construct a network that includes all of them (http:// www.networkanalyst.ca).

Gene network analysis using STRING showed that the 2 most interesting enriched KEGG pathways in the constructed network were the cytokine-cytokine receptor interaction $(P$-value $=2.379 \mathrm{E}-07)$, in which $14 \mathrm{DE}$ genes were unique to this pathway and the cell adhesion molecules (CAM; $P$-value $=0.00018)$, and 10 of our DE genes were present (Figure 4). Both of these pathways were considered relevant due to their connection to host immune response, having a high FDR and at least 10 genes involved (Szklarczyk et al., 2017). NetworkAnalyst was used to perform a gene network analysis for tissue specific PPI, with breast mammary tissue as the target tissue. Fold change of the DE genes was also uploaded into NetworkAnalyst, thus allowing for expression levels of the DE genes to be taken into account. This analysis found the highest enriched pathways were the cytokine-cytokine interaction pathways for the upregulated genes as well as the CAM pathway for the downregulated genes (Figure 5). In the cytokine-cytokine interaction pathway, 20 of our $\mathrm{DE}$ genes were involved $(P$-value $=1.59 \mathrm{E}-14)$, whereas in the CAM pathway, 6 of our DE genes were present $(P$-value $=0.000525)$. As presented, the results from both of the gene network analysis are in concordance with each other.

\section{Cytokine-Cytokine Receptor Interaction}

As presented in Figures 4 and 5, all of the genes involved in the cytokine-cytokine receptor interac- 


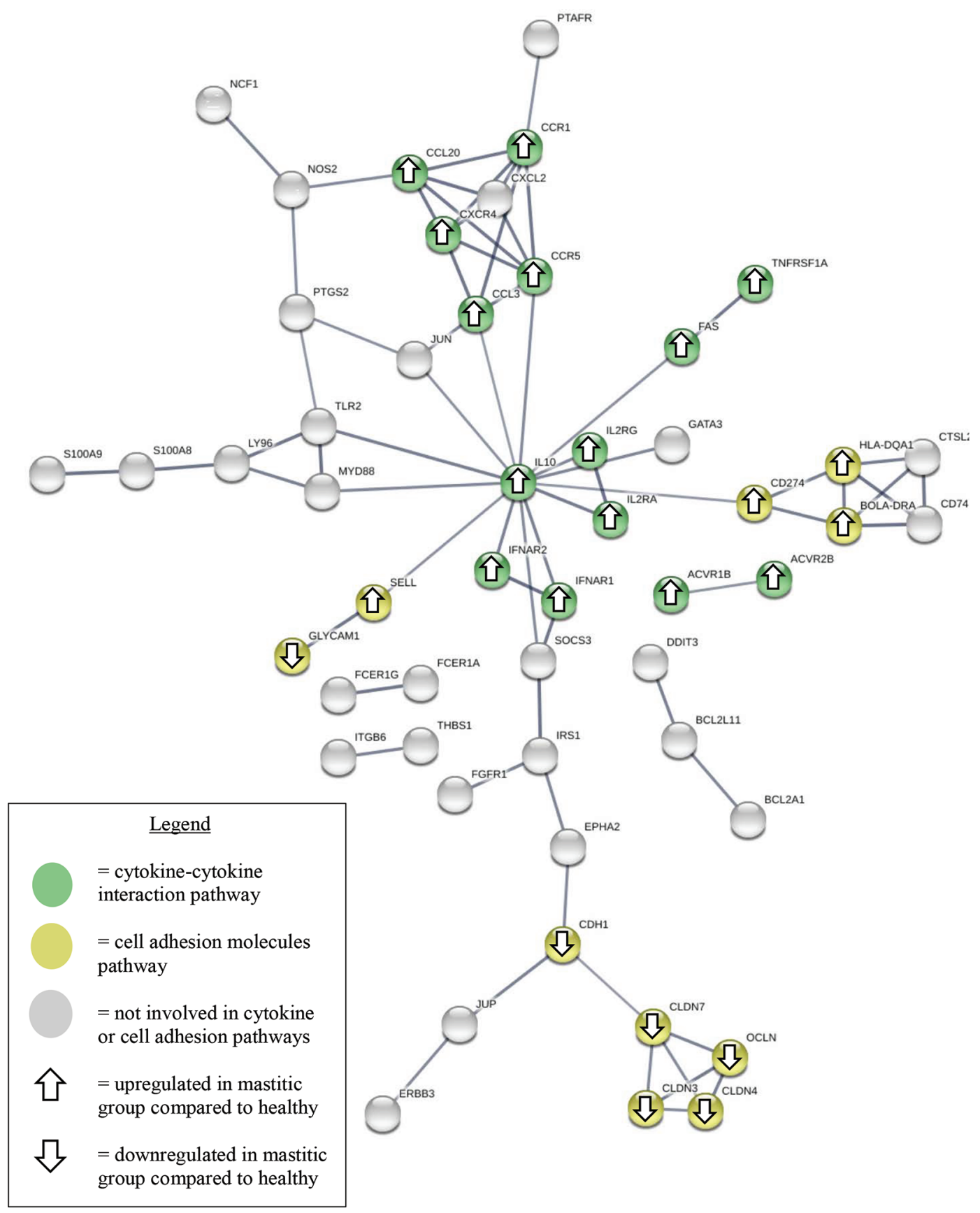

Figure 4. Gene network analysis using the list of 102 unique differentially expressed (DE) genes involved in the 2 significant metabolic pathways (cytokine-cytokine interaction and cell adhesion molecules) using STRING software (https://string-db.org). The green circles represent the genes involved in the cytokine-cytokine interaction pathway; the yellow circles represent the genes involved in the cell adhesion molecules pathway; the gray circles represent the genes not involved in either the cytokine-cytokine interaction pathway or the cell adhesion molecule pathway. The up arrows represent the genes that are upregulated in the mastitic group compared with the healthy group; the down arrows represent the genes that are downregulated in the mastitic group compared with the healthy group.

tion pathway were upregulated in the mastitic group compared with the healthy group based on their FC values. This is interesting to consider as there are specific groups of cytokines involved in this pathway such as chemokines, interleukins, interferon, and tumor necrosis factor. In terms of an IMI, there is an influx of a foreign particle that stimulates an immune response to clear the pathogen from the mammary gland. The trafficking of immune cells from primary lymphoid tissues to circulation (blood and lymph) then to the 


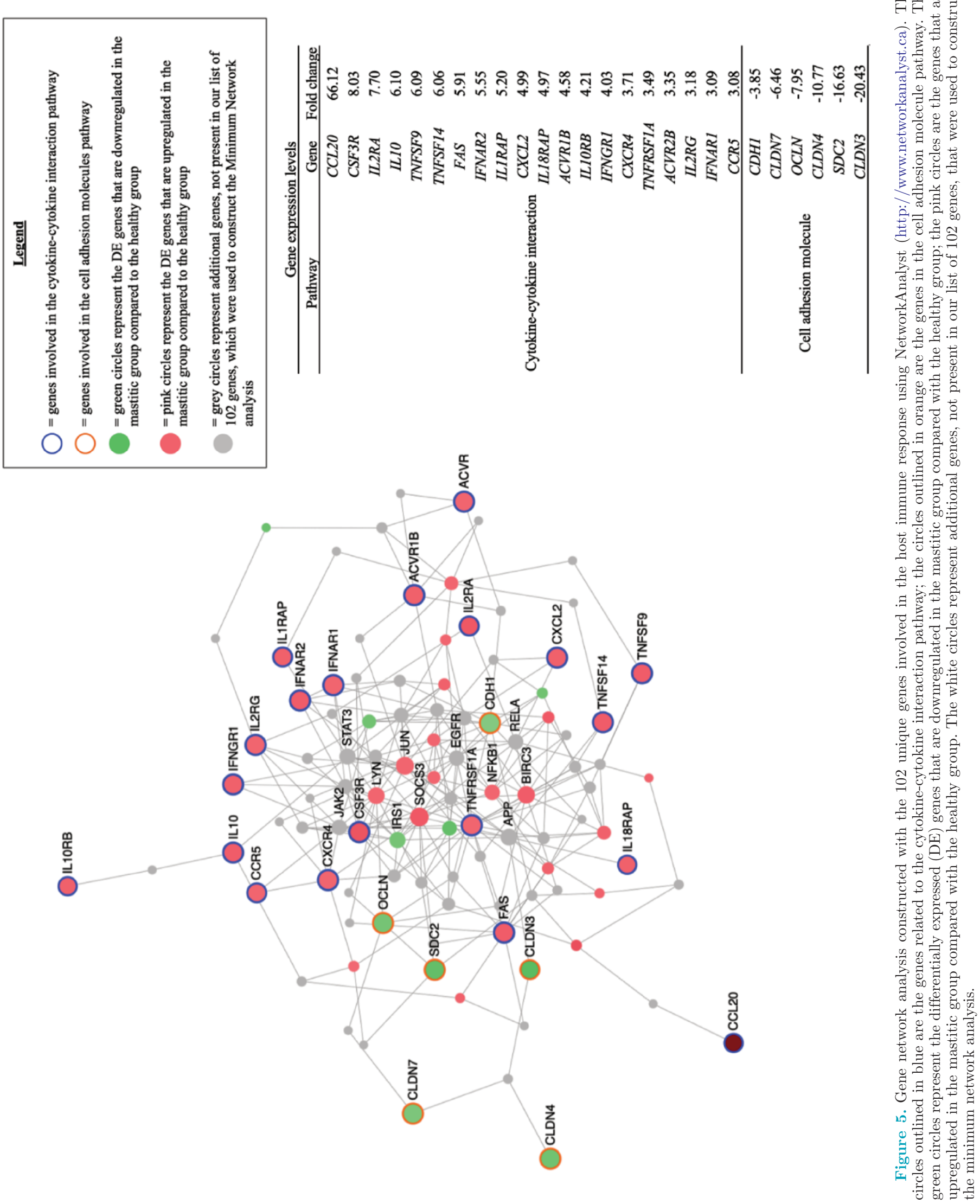


mammary gland during an IMI is dependent on the mixture of chemokines and chemoattractants (Zhang and An, 2007). Both of these fall under a broad category of small proteins known as cytokines, which can either be pro-inflammatory (IL-1, IL-6, and TNF- $\alpha$ ) or anti-inflammatory (IL-4, IL-10, and IL-11; Zhang and An, 2007). Pro-inflammatory cytokines promote inflammation, which can make some diseases worse (Dinarello, 2000), whereas anti-inflammatory cytokines aim to reduce inflammation and promote healing. In the mammary gland, this is very important because the faster the mammary gland is able to clear the infection, the better the animal will be. One interleukin, IL-10, is present at the center of the network in Figure 4 and illustrates its importance in the functionality of all the other genes involved in the cytokine-cytokine receptor pathway, as well as the CAM pathway. Interleukin-10 is able to repress the expression of certain inflammatory cytokines such as IL-1, IL-6, and TNF- $\alpha$ (Zhang and An, 2007); however, this was not observed in our data. Both IL-10 as well as pro-inflammatory cytokines were upregulated in the mastitis group.

\section{Cell Adhesion Molecules}

Another important part of the host immune system involves adhesion molecules. This is a very important pathway to consider as CAM (i.e., selectins, integrins, and immunoglobulins) play a central role in cell migration, proliferation, survival, and apoptosis (Golias et al., 2011), which are all important factors in the development and maintenance of tissues (Khalili and Ahmad, 2015). They are also involved in regulation of inflammatory and immune responses (Golias et al., 2011). As this pathway encourages cells to adhere together or the extracellular matrix (Golias et al., 2011), it could play a potential role in the formation of the mucus plug. The mucus plug could produce a more efficient mammary gland barrier to protect the host from the external environment (Hoorens et al., 2011), thus preventing some cases of IMI. Due to the importance of this pathway, we were further interested in identifying which unique genes were present in this pathway. Two BoLA genes and the CD274 molecule were upregulated in the mastitic group compared with the healthy group. However, in one cluster of genes, the claudin genes $(C L D N)$ and the ocludin genes $(O C L N)$ were downregulated in the mastitic group; these 2 structural protein families are the 2 key constituents of tight junctions (Stelwagen and Singh, 2014). Tight junctions are cellular structures that facilitate cell-cell communication and are important to maintain the structure of epithelia (Stelwagen and Singh, 2014). However, during a case of IMI, tight junction integrity is compromised, allowing for blood-borne immune factors to enter the mammary gland, also allowing multiple pathogens to enter the epithelium (Lehmann et al., 2013). In our study, 4 of these tight junction genes were downregulated in the mastitic group compared with the healthy group (OCLN; claudin-3, CLDN3; claudin-4, CLDN4; and claudin-7, $C L D N^{7}$ ). Similarly, the glycosylationdependent cell adhesion molecule 1 (GLYCAM1) gene was also downregulated.

\section{Identification of Functional Candidates Associated with Immune Processes Among Highly Differently Expressed Genes}

Results from transcriptomics (RNA-Seq) combined with the functional analysis were integrated using a Venn diagram to create a list of functional candidate genes with a potential effect on host defense to mastitis (Figure 6). Among them, the criteria used to overlap the genes was as follows: (1) the highly expressed genes $(\mathrm{RPKM} \geq 500)$ in both healthy and mastitic groups (n $=19),(2)$ the list of DE genes between healthy and mastitic groups $(\mathrm{n}=449)$, and (3) genes involved in the significantly enriched metabolic pathway analysis $(\mathrm{n}=$ 117). Seven genes were identified as being present in all 3 groups of criteria: GLYCAM1, B2M, CD 74 , BoLA$D R A$, Fc fragment of $\operatorname{IgE}$ receptor $\operatorname{Ig}(F C E R 1 G), S D S$, and NF $\kappa \mathrm{B}$ inhibitor $\alpha(N F K B I A)$ and thus are considered our functional candidate genes for further analysis (Table 4).

The first gene, GLYCAM1, is a mucin-like endothelial glycoprotein and is a component of the milk fat globule membrane (Dowbenko et al., 1993; Le Provost et al., 2003). This gene is expressed during lactation by mammary epithelial cells, as well as in the epithelial cells of the peripheral and mesenteric lymph nodes (Dowbenko et al., 1993). As mentioned, mucins play an important role in protection as they trap pathogens and are a key component of the mucus plug. The GLYCAM1 gene was underexpressed in the mastitic teats compared with the healthy teats $(\mathrm{FC}=-55.59)$, and therefore, this could potentially affect the susceptibility to IMI in the mastitic quarter. Le Provost et al. (2003) compared the GLYCAM1 promotor sequence across 4 species (mouse, cow, camel, and human) and found that the regulatory elements (signal transducers and activators of transcription, nuclear factor I, and glucocorticoid receptor) were conserved across all 4 species supporting that this is important in the transcriptional regulation of the GLYCAM1 gene. In this study we did not look to see if there were any variants in the GLYCAM1 gene promoter region; however, future analysis will aim to 

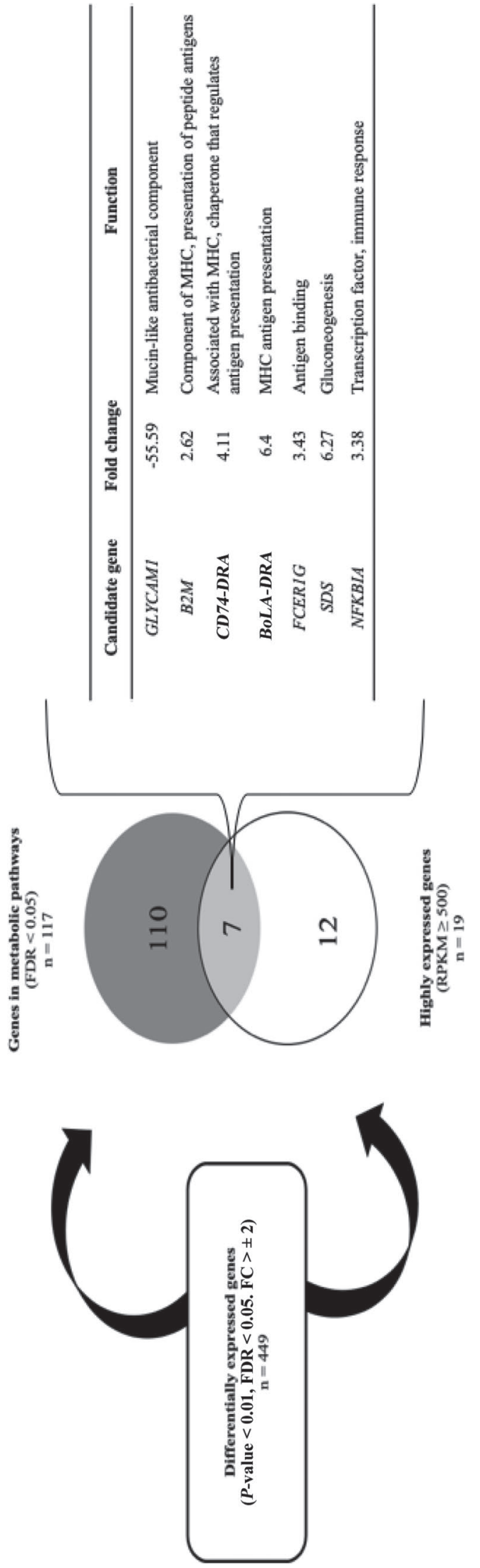

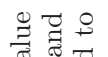

政

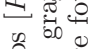

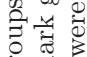

品

용

它

药

$\pi, 5$

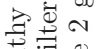

呵

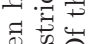

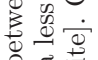

- 0

要超

藏

次

.

붕

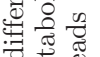

पै

苛 苨

承绻

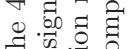

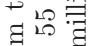

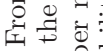

ن.

诺

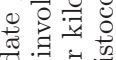

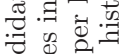

鸪

15

원

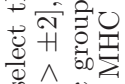

कठ

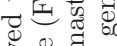

(5)

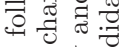

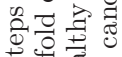

in

g

$\vec{\circ} V \overrightarrow{0}$

굴.

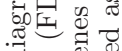

50

.

害

过

\% . 의

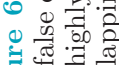

$\exists$ 匹ٓ

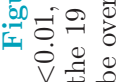

identify if there is a variation in this region, or among other regions in the GLYCAM1 gene, that may result in different levels of expression for this gene, and therefore affect its potential in the formation of the mucus plug.

The B2M gene was DE between healthy and mastitic groups. The B2M gene is known to be associated with BoLA and multiple immune regulatory mechanisms of defense toward internal or invasive threats (Liu et al., 2018). The B2M protein is classically known for its noncovalent association with class I BoLA, which present endogenous antigens associated with cancerous cells and viral-infected cell CD8+ T-lymphocytes that subsequently kill the cell (Behl et al., 2012). More recently, a $9-\mathrm{kD}$ fragment of $B 2 M$ was shown to possess antibacterial activity against $S$. aureus, and may function as a monocyte chemoattractant (Chiou et al., 2016). In beef cattle, 12 mutations in the B2M gene were associated with changes in milk protein and $\mathrm{IgG}$, which led to an elevated SCC (Clawson et al., 2004; Sanchez et al., 2004). A recent study by Liu et al. (2018) also found that 5 mutations were present in the $B 2 M$ gene associated with milk protein and SCC in Chinese Holstein dairy cows. In our study, this gene was overexpressed in the mastitic group $(\mathrm{FC}=2.62)$ in comparison to the healthy group.

The CD74 molecule (BoLA class II invariant chain) is a glycoprotein and is also involved with BoLA as it has a variety of functions associated with the cow's immune response and plays a role in antigen presentation pathways ( $\mathrm{Su}$ et al., 2017). The CD74 molecule is expressed on the cell surface of BoLA class II positive cells, such as dendritic cells, macrophages, and B cells, which are the 3 key APC. This gene was overexpressed $(\mathrm{FC}=4.11)$ in the mastitic group in comparison to the healthy group. In humans, $C D^{7} 4$ is also involved with the MHC complex as it acts as an MHC class II chaperone, which is important to initiate immune function (Su et al., 2017). The CD/4 molecule also displaces the small peptide (class II-associated invariant chain peptide) from the MHC binding groove on $\mathrm{MHC}$ class II molecules, which is key for antigen presentation (Jones et al., 1979). It is also present on cell types other than APC (Beswick and Reyes, 2009) and is directly involved with many inflammatory diseases in humans, such as liver fibrosis, systemic lupus, and Alzheimer's disease (Su et al., 2017). Various studies support that $C D$ 74 is involved with inflammatory diseases (Beswick and Reyes, 2009; Su et al., 2017), but to the best of our knowledge, it has not been linked with mastitis in dairy cows. However, the presence of variants in the sequence of this gene may result in cows that are susceptible to mastitis infections.

Another important gene, BoLA-DRA, was overexpressed $(\mathrm{FC}=6.40)$ in the mastitic group compared 
Table 4. Potential functional candidate genes differentially expressed between healthy and mastitic groups and their associated significance levels $^{1}$

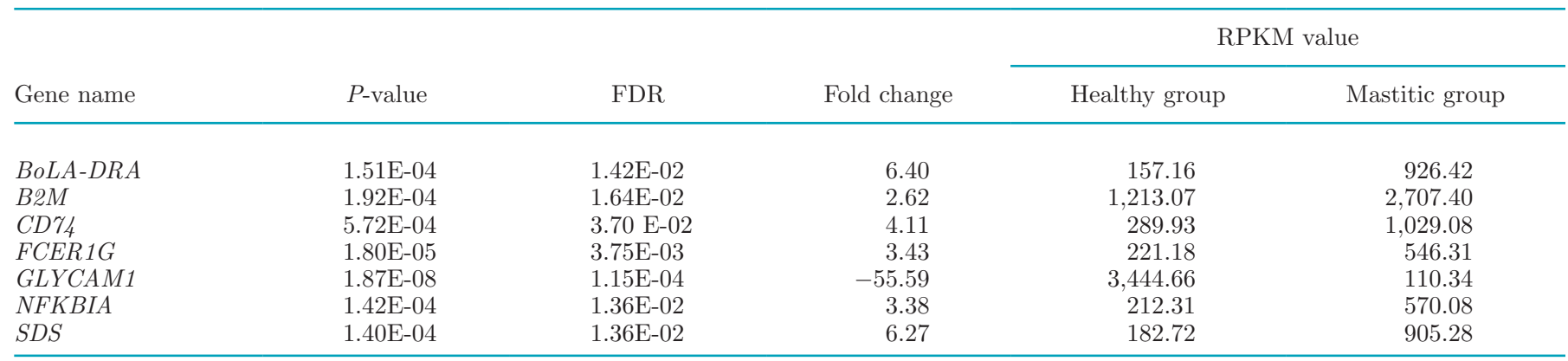

${ }^{1}$ All genes present in metabolic pathways $P$-value adjusted false discovery rate $($ FDR $)<0.05 . B 2 M=$ B2-microglobulin; $G L Y C A M 1=$ glycosylation-dependent cell adhesion molecule $1 ; C D 74=\mathrm{CD} 74$ molecule; NFKBIA = NFKB inhibitor $\alpha ; F C E R 1 G=\mathrm{fc}$ fragment of IgE receptor Ig; and $S D S=$ serine debydratase. RPKM = reads per kilobase per million mapped reads.

with the healthy group. The BoLA DR class II molecules are essential in presenting exogeneous antigens to CD4+ T-lymphocytes that drive cellular as well as antibody-mediated immune response. Some BoLA genes are highly polymorphic and therefore directly contribute to animal-to-animal variation in the ability to recognize antigens and carry out antigen presentation (Tao and Mallard, 2007). Certain BoLA DRB alleles have been attributed to lower SCC, whereas others are associated with higher SCC. Similarly, some have been associated with higher mastitis risk, whereas others are associated with lower mastitis risk (Rupp et al., 2007). Therefore, when looking into increasing the cow's mastitis resistance, focusing on the BoLA alleles and genes that are present in BoLA pathways could provide a variety of information that may aid in the selection for improved health and increased mastitis resistance.

The next gene, FCER1G, was overexpressed (FC = $3.43)$ in the mastitic group compared with the healthy group. The FC receptors are present on the surfaces of cells and bind to specific immunoglobulins ( $\operatorname{IgG}, \operatorname{IgE}$, and $\operatorname{IgA}$ ) based on the shape of the antigen binding regions (Garman et al., 2001; Woof and Burton, 2004). This recognition ensures that the immunoglobulin molecules are able to eliminate bacteria, viruses, and parasites from the body (Woof and Burton, 2004). For this gene, the immunoglobulin of interest is $\operatorname{IgE}$, which helps to protect against parasitic infections and is a key molecule involved with allergic reactions (Woof and Burton, 2004).

The $S D S$ gene was overexpressed in the mastitic group compared with the healthy group $(\mathrm{FC}=6.27)$. Serine dehydratase is essential for gluconeogenesis, as serine dehydratase catalyzes the deamination of Lserine to pyruvate (López-Flores et al., 2006). In dairy cows, gluconeogenesis is critical during lactation for high-producing dairy cows because glucose demand increases to maintain adequate glucose supply for the mammary gland (Lemon and Nagle, 1981; Aschenbach et al., 2010).

Last, the NFKBIA gene was overexpressed $(\mathrm{FC}=$ 3.38 ) in the mastitic group and is present in the inflammatory pathway NFkB. The NFKBIA gene plays a significant role in the regulation of immune response and inflammation through its ability to induce transcription of pro-inflammatory genes, such as cytokines, chemokines, and adhesion molecules (Tak and Firestein, 2001; Lawrence, 2009; Yang et al., 2012; Zhao et al., 2012b). The NFKBIA gene product interacts with REL dimers, which then inhibit the NFkB transcription factor, blocking the ability of NFkB to bind DNA (Huang et al., 2014). During mastitis, inhibition of this pathway might decrease the severity of mastitis infections, but further research is needed into this gene.

\section{DE Genes Related to Mastitis QTL Regions}

Quantitative trait loci allow researchers to link complex phenotypes, such as mastitis resistance, to specific regions of chromosomes (Miles and Wayne, 2008). The current cattle QTL database contains 113,256 QTL representing 599 different traits (release $35 ; \mathrm{Hu}$ et al., 2016; https://www.animalgenome.org/cgi-bin/QTLdb/ BT/index). These QTL are distributed across all the bovine chromosomes and the number of QTL reported range from 718 on chromosome 28 to 25,692 QTL reported on the bovine $\mathrm{X}$ chromosome. Among these 113,256 QTL focusing on mastitis resistance, 167 QTL are related to CM, 77 QTL are associated with SCC, and 1,072 QTL are associated with SCS (release 35; Hu et al., 2016; https://www.animalgenome.org/cgi-bin/ QTLdb/BT/index). Identifying those genes within QTL regions can provide additional positional relevance 
to the functional, statistical, and biological relevance to increase mastitis resistance. Therefore, this provides a potential solution to tackle this complex trait.

We identified that out of the list of $449 \mathrm{DE}$ genes, 177 were located in QTL regions associated with SCS, 20 were located in QTL regions associated with SCC, and 43 were located in QTL regions associated with CM (Supplemental Table S3; https://doi.org/10.3168/jds .2019-16504). Three chromosomes, 5, 18, and 19, had 25, 47, and 38 associated QTL, respectively. In all 3 of these chromosomes, the trait most commonly linked with the QTL was SCS. Within these 449 genes, 62 genes were associated with several QTL related to mastitis. Among them, 2 genes, lysine methyltransferase 2D (KMT2D) and gamma-secretase activating protein $(G S A P)$, each were positioned in $4 \mathrm{QTL}$, while the rest of the genes had 2 or 3 QTL regions associated with them. The KMT2D encodes a highly conserved protein belonging to the SET1 family of histone lysine methyltransferase (Zhang et al., 2015). The KMT2D gene had one QTL associated with CM and 3 associated with SCS. Due to the large confidence interval of these QTL, further research is needed to determine if these genes could contain causal quantitative trait nucleotides associated with mastitis. The next gene, GSAP selectively increases amyloid- $\beta$ production, which has been linked with Alzheimer's in humans (He et al., 2010). This gene had 2 QTL linked with CM, one linked with SCC and one linked with SCS. To the best of our knowledge, this gene has not yet been linked with mastitis in dairy cattle, and thus, further research is needed to confirm these results.

Three additional genes [GLYCAM1, BoLA-DRA, and lactalbumin $\alpha(L A L B A)$ ] were associated with QTL regions for SCS, and all of these genes were not only DE but also highly expressed (RPKM > 500; Table 5). The $L A L B A$ gene was also located in a QTL region associated with CM. This gene encodes $\alpha$-LA protein, which is a principal protein of milk and plays a key role in the biosynthesis of lactose (Zidi et al., 2014). To the best of our knowledge, this gene has not been directly linked with CM and SCS; however, due to the large confidence interval of QTL, this gene can be located within the QTL region but may not actually affect the mastitis traits. The GLYCAM1 gene, which is also one of the functional candidate genes previously discussed, was positioned within a QTL region linked to SCS on chromosome 5. As mucins play an important role in protection as well as inflammatory responses, this could provide reasoning as to why a QTL region within the GLYCAM1 gene could be responsible for an observed phenotypic variation in healthy and mastitic cows. Next, the BoLA-DRA gene located on chromosome 23 was also a candidate gene is associated with a QTL linked with SCS (Table 5). The BoLA class II molecules are responsible for presenting exogeneous antigens to the BoLA complex. In general, the BoLA molecules are key for antigen presentation (Vandre et al., 2014), and as discussed previously, the BoLA complex is critical in the development of the immune system, and genes that regulate this process can determine susceptibility or resistance to various diseases (Behl et al., 2012) and therefore affect resistance to IMI. Therefore, due to these genes being present within QTL regions associated with SCS, this could affect the host's phenotypic variation in mastitis resistance due to higher levels of SC in the milk, which reflects the presence of mastitis, leading to significant loses of milk production and increased health costs (CDN, 2001). Although only 2 candidate genes had a direct effect on SCS, SCC, or CM, 5 QTL have been reported to be associated with the genomic region for the functional candidate gene FCER $1 G$, which is another functional candidate gene. These QTL are associated with calving to conception interval, daughter pregnancy rate, first service conception, inseminations per conception, and milk protein percentage, which is indirectly associated with mastitis (release 35; Hu et al., 2016; https:// www.animalgenome.org/cgi-bin/QTLdb/BT/genesrch $?$ gwords $=$ FCER1G\&submit $=$ go). As mastitis resistance is genetically correlated with milk production traits (Lund et al., 2008), if this QTL affects milk pro-

Table 5. QTL regions within the 19 highly expressed genes in healthy and mastitic samples ${ }^{1}$

\begin{tabular}{|c|c|c|c|c|c|c|c|c|c|}
\hline Gene & \multicolumn{3}{|c|}{ Gene region } & \multicolumn{3}{|c|}{ QTL region } & \multicolumn{2}{|c|}{ RPKM value } & $\begin{array}{l}\text { QTL } \\
\text { trait } \\
\text { name }\end{array}$ \\
\hline$L A L B A$ & 5 & $31,347,861$ & $31,349,882$ & 5 & $28,229,734$ & $44,520,234$ & $1,555.74$ & 160.16 & SCS \\
\hline$L A L B A$ & 5 & $31,347,861$ & $31,349,882$ & 5 & $18,794,396$ & $71,053,139$ & $1,555.74$ & 160.16 & SCS \\
\hline$L A L B A$ & 5 & $31,347,861$ & $31,349,882$ & 5 & $30,747,653$ & $32,571,641$ & $1,555.74$ & 160.16 & $\mathrm{CM}$ \\
\hline
\end{tabular}

${ }^{1} \mathrm{RPKM}=$ reads per kilobase per million mapped reads; $\mathrm{CM}=$ clinical mastitis; BoLA-DRA = major histocompatibility complex, class II, DR $\alpha ; G L Y C A M 1=$ glycosylation-dependent cell adhesion molecule 1 ; and $L A L B A=$ lactalbumin $\alpha$. 
tein production, this could potentially affect mastitis resistance as well, which could be due to a pleiotropic effect controlling the phenotype of several different and unrelated traits.

\section{CONCLUSIONS}

In summary, $449 \mathrm{DE}$ genes between healthy and mastitic Holstein milk SC samples were identified using RNA-Seq technology. In the healthy group, the 5 genes with the highest expression (ranging from 5,059 to $10,808.45$ RPKM) were associated with milk components, and the average $\mathrm{FC}$ value was -30.80 . This means that in the mastitic quarter of the mammary gland, these critical milk component genes were $30 \times$ underexpressed in comparison to the healthy quarter, illustrating that the mammary gland stops being a milk producer and aims to protect itself from the IMI. In the mastitic group, the 5 genes with the highest expression (ranging from 771.75 to 2,707.40 RPKM) were associated with immune response and had an average $\mathrm{FC}$ value of 4.52 , meaning these genes were $4 \times$ overexpressed in the mastitic group compared with the healthy group. In silico functional analysis using the list of 449 DE genes identified 36 significant metabolic pathways associated with host defense. Seven potential functional candidate genes (GLYCAM1, B2M, CD74, BoLA-DRA, FCER1G, SDS, and NFKBIA) associated with mastitis susceptibility and resistance were identified, integrating results from transcriptomic and functional analysis. Moreover, several of the functional genes found in our study had additional positional evidence of being associated with mastitis, as they were found in QTL regions related to CM, SCC, and SCS. Two of the 7 functional candidate genes identified (GLYCAM1 and BoLA-DRA) are both associated with QTL regions linked with SCS. In conclusion, further investigation will include the identification of potential SNP located in the list of 7 functional candidate genes associated with mastitis susceptibility and resistance.

\section{ACKNOWLEDGMENTS}

This study was funded by the Ontario Agri-Food Innovation Alliance [Ontario Ministry of Agriculture, Food and Rural Affairs (OMAFRA), Guelph, Ontario, Canada] and Natural Sciences and Engineering Research Council of Canada (Ottawa, Ontario, Canada). This paper is also a contribution to the Food from Thought research program supported by the Canada First Research Excellence Fund. We also sincerely thank Douglas Gisi at the University of California Dairy, University of California-Davis, for collecting all of the milk samples used in this study.

\section{REFERENCES}

Aschenbach, J. R., N. B. Kristensen, S. S. Donkin, H. M. Hammon, and G. B. Penner. 2010. Gluconeogenesis in dairy cows: The secret of making sweet milk from sour dough. IUBMB Life 62:869-877. https://doi.org/10.1002/iub.400.

Baltian, L. R., M. V. Ripoli, S. Sanfilippo, S. N. Takeshima, Y. Aida, and G. Giovambattista. 2012. Association between BoLA-DRB3 and somatic cell count in Holstein cattle from Argentina. Mol. Biol. Rep. 39:7215-7220. https://doi.org/10.1007/s11033-012-1526 $-\mathrm{y}$.

Behl, J. D., N. K. Verma, N. Tyagi, P. Mishra, R. Behl, and B. K. Joshi. 2012. The major histocompatibility complex in bovines: A review. ISRN Vet. Sci. 2012:872710. https://doi.org/10.5402/ $2012 / 872710$.

Beswick, E. J., and V. E. Reyes. 2009. CD74 in antigen presentation, inflammation, and cancers of the gastrointestinal tract. World J. Gastroenterol. 15:2855-2861. https://doi.org/10.3748/wjg.15 .2855 .

Bogin, E., G. Ziv, J. Avidor, B. Rivetz, S. Gordin, and A. Saran. 1977. Distribution of lactate dehydrogenase isoenzymes in normal and inflamed bovine udder and milk. Res. Vet. Sci. 22:198-200.

Cánovas, A., A. Reverter, K. L. DeAtley, R. L. Ashley, M. L. Colgrave, M. R. S. Fortes, A. Isla-Trejo, S. Lehnert, L. Porto-Neto, G. Rincón, G. A. Silver, W. M. Snelling, J. F. Medrano, and M. G. Thomas. 2014b. Multi-tissue omics analyses reveal molecular regulatory networks for puberty in composite beef cattle. PLoS One 9:e102551. https://doi.org/10.1371/journal.pone.0102551.

Cánovas, A., G. Rincón, C. Bevilacqua, A. Islas-Trejo, P. Brenaut, R. C. Hovey, M. Boutinard, C. Morgenthaler, M. K. VanKlompenberg, P. Martin, and J. F. Medrano. 2014a. Comparison of five different RNA sources to examine the lactating bovine mammary gland transcriptome using RNA-Sequencing. Sci. Rep. 4:5297. https://doi.org/10.1038/srep05297.

Cánovas, A., G. Rincón, A. Islas-Trejo, R. Jimenez-Flores, A. Laubscher, and J. F. Medrano. 2013. RNA sequencing to study gene expression and single nucleotide polymorphism variation associated with citrate content in cow milk. J. Dairy Sci. 96:2637-2648. https://doi.org/10.3168/jds.2012-6213.

Cánovas, A., G. Rincon, A. Islas-Trejo, S. Wickramasinghe, and J. F. Medrano. 2010. SNP discovery in the bovine milk transcriptome using RNA-Seq technology. Mamm. Genome 21:592-598. https:// doi.org/10.1007/s00335-010-9297-z.

Cardoso, T. F., R. Quintanilla, A. Castelló, R. González-Prendes, M. Amills, and A. Cánovas. 2018. Differential expression of mRNA isoforms in the skeletal muscle of pigs with distinct growth and fatness profiles. BMC Genomics 19:145. https://doi.org/10.1186/ s12864-018-4515-2.

Carlén, E., E. Strandberg, and A. Roth. 2004. Genetic Parameters for clinical mastitis, somatic cell score, and production in the first three lactations of Swedish Holstein cows. J. Dairy Sci. 87:30623070. https://doi.org/10.3168/jds.S0022-0302(04)73439-6.

CattleQTLdb. Release 35; April 29, 2018. Accessed May 28, 2018. https://www.animalgenome.org/cgi-bin/QTLdb/BT/index.

CDN. 2001. Somatic Cell Score: Relating Bull Proofs to Daughter Performance. Accessed Apr. 19, 2018. https://www.cdn.ca/articles .php.

Chami, B., N. Barrie, X. Cai, X. Wang, M. Paul, R. Morton-Chandra, A. Sharland, J. M. Dennis, S. B. Freedman, and P. K. Witting. 2015. Serum amyloid a receptor blockade and incorporation into high-density lipoprotein modulates its pro-inflammatory and prothrombotic activities on vascular endothelial cells. Int. J. Mol. Sci. 16:11101-11124. https://doi.org/10.3390/ijms160511101.

Chiou, S. J., C. C. Wang, Y. S. Tseng, Y. J. Lee, S. C. Chen, C. H. Chou, L. Y. Chuang, Y. R. Hong, C. Y. Lu, C. C. Chiu, and M. Chignard. 2016. A novel role for $\beta 2$-microglobulin: A precursor of antibacterial chemokine in respiratory epithelial cells. Sci. Rep. 6:31035. https://doi.org/10.1038/srep31035.

Clawson, M. L., M. P. Heaton, C. G. Chitko-McKown, J. M. Fox, T. P. L. Smith, W. M. Snelling, J. W. Keele, and W. W. Laegreid. 2004. Beta-2-microglobulin haplotypes in U.S. beef cattle and associa- 
tion with failure of passive transfer in newborn calves. Mamm. Genome 15:227-236. https://doi.org/10.1007/s00335-003-2320-x.

Corfield, A. P. 2015. Mucins: A biologically relevant glycan barrier in mucosal protection. Biochim. Biophys. Acta 1850:236-252. https:/ /doi.org/10.1016/j.bbagen.2014.05.003.

Coulon, J. B., C. Hurtaud, B. Remond, and R. Verite. 1998. Factors contributing to variation in the proportion of casein in cows' milk true protein: A review of recent INRA experiments. J. Dairy Res. 65:375-387. https://doi.org/10.1017/S0022029998002866.

Dhanisha, S. S., C. Guruvayoorappan, S. Drishya, and P. Abeesh. 2018. Mucins: Structural diversity, biosynthesis, its role in pathogenesis and as possible therapeutic agents. Crit. Rev. Oncog. Hematol. 122:98-122. https://doi.org/10.1016/j.critrevonc.2017.12.006.

Dinarello, C. A. 2000. Proinflammatory cytokines. Chest 118:503-508

Dowbenko, D., A. Kikuta, C. Fennie, N. Gillett, and L. A. Lasky. 1993 Glycosylation-dependent cell adhesion molecule 1 (GLYCAM 1) mucin is expressed by lactating mammary gland epithelial cells and is present in milk. J. Clin. Invest. 92:952-960. https://doi.org/ 10.1172/JCI116671.

Eigel, W. N., J. E. Butler, C. A. Ernstrom, H. M. Farrell, V. R. Halwarkar, R. Jenness, and R. M. Whitney. 1984. Nomenclature of proteins of cow's milk: Fifth revision. J. Dairy Sci. 67:1599-1631. https://doi.org/10.3168/jds.S0022-0302(84)81485-X.

Garman, S. C., S. Sechi, J. P. Kinet, and T. S. Jardetzky. 2001. The analysis of the human high affinity IgE receptor FceRI from multiple crystal forms. J. Mol. Biol. 311:1049-1062. https://doi.org/ 10.1006/jmbi.2001.4929.

Gerardi, G., D. Bernardini, C. Azzurra Elia, V. Ferrari, L. Iob, and S. Segato. 2009. Use of serum amyloid A and milk amyloid A in the diagnosis of subclinical mastitis in dairy cows. J. Dairy Res. 76:411-417. https://doi.org/10.1017/S0022029909990057.

Godden, S. M., E. Royster, J. Timmerman, P. Rapnicki, and H. Green 2017. Evaluation of an automated milk leukocyte differential test and the California mastitis test for detecting intramammary infection in early- and late-lactation quarters and cows. J. Dairy Sci. 100:6527-6544. https://doi.org/10.3168/jds.2017-12548.

Golias, C., A. Batistatou, G. Bablekos, A. Charalabopoulos, D. Peschos, P. Mitsopoulos, and K. Charalabopoulos. 2011. Physiology and pathophysiology of selectins, integrin's, and IgSf cell adhesion molecules focusing on inflammation. A paradigm model on infectious endocarditis. Cell Commun. Adhes. 18:19-32. https:// doi.org/10.3109/15419061.2011.606381.

Guerrero, A., A. C. Dallas, S. Contreras, A. Bhandari, A. Cánovas, A. Islas-Trejo, J. F. Medrano, E. A. Parker, M. Wang, K. Hettinga, S. Chee, J. B. German, D. Barile, and C. B. Lebrilla. 2015. Peptidomic analysis of healthy and subclinically mastitic bovine milk. Int. Dairy J. 46:46-52. https://doi.org/10.1016/j.idairyj.2014.09.006.

Harmon, R. J. 1994. Physiology of mastitis and factors affecting somatic cell counts. J. Dairy Sci. 77:2103-2112. https://doi.org/10 .3168/jds.S0022-0302(94)77153-8.

He, G., W. Luo, P. Li, C. Remmers, W. Netzer, J. Hendrick, K. Bettayeb, M. Flajolet, F. Gorelick, L. P. Wennogle, and P. Greengard. 2010. Gamma-secretase activating protein, a therapeutic target for Alzheimer's disease. Nature 467:95-98. https://doi.org/10.1038/ nature09325.

Heringstad, B., Y. M. Chang, D. Gianola, and G. Klemetsdal. 2005. Genetic association between susceptibility to clinical mastitis and protein yield in Norwegian dairy cattle. J. Dairy Sci. 88:15091514. https://doi.org/10.3168/jds.S0022-0302(05)72819-8.

Hogarth, C. J., J. L. Fitzpatrick, A. M. Nolan, F. J. Young, A. Pitt, and P. D. Eckersall. 2004. Differential protein composition of bovine whey: a comparison of whey from healthy animals and from those with clinical mastitis. Proteomics 4:2094-2100. https://doi .org/10.1002/pmic.200300723.

Hoorens, P. R., M. Rinaldi, R. W. Li, B. Goddeeris, E. Claerebout, J. Vercruysse, and P. Geldhof. 2011. Genome wide analysis of bovine mucin genes and their gastrointestinal transcription profile. BMC Genomics 12:140-151. https://doi.org/10.1186/1471-2164-12-140.

Hu, Z. L., C. A. Park, and J. M. Reecy. 2016. Developmental progress and current status of the Animal QTLdb. Nucleic Acids Res. 44:D827-D833. https://doi.org/10.1093/nar/gkv1233.
Huang, F., J. Tang, X. Zhuang, Y. Zhuang, W. Cheng, W. Chen, H. Yao, and S. Zhang. 2014. MiR-196a promotes pancreatic cancer progression by targeting nuclear factor kappa-B-inhibitor alpha. PLoS One 9:e87897. https://doi.org/10.1371/journal.pone .0087897 .

Jones, P. P., D. B. Murphy, D. Hewgill, and H. O. McDevitt. 1979. Detection of a common polypeptide chain in $I-A$ and $I-E$ sub-region immunoprecipitates. Mol. Immunol. 16:51-60. https://doi.org/10 .1016/0161-5890(79)90027-0.

Jørgensen, C. H., A. R. Kristensen, S. Østergaard, and T. W. Bennedsgaard. 2016. Use of inline measures of L-lactate dehydrogenase for classification of posttreatment mammary Staphylococcus aureus infection status in dairy cows. J. Dairy Sci. 99:8375-8383. https://doi.org/10.3168/jds.2016-10858.

Kamiñski, S., A. Cieœliñska, and E. Kostyra. 2007. Polymorphism of bovine beta-casein and its potential effect on human health. J. Appl. Genet. 48:189-198. https://doi.org/10.1007/BF03195213.

Khalili, A. A., and M. R. Ahmad. 2015. A review of cell adhesion studies for biomedical and biological applications. Int. J. Mol. Sci. 16:18149-18184. https://doi.org/10.3390/ijms160818149.

Kontopidis, G., C. Holt, and L. Sawyer. 2004. Invited review: $\beta$-lactoglobulin: Binding properties, structure, and function. J. Dairy Sci. 87:785-796. https://doi.org/10.3168/jds.S0022 $-0302(04) 73222-1$.

Kroll, J. E., J. Kim, L. Ohno-Machado, and S. J. de Souza. 2015. Splicing Express: a software suite for alternative splicing analysis using next-generation sequencing data. PeerJ 3:e1419. https://doi .org/10.7717/peerj.1419.

Lawrence, T. 2009. The nuclear factor NF-kappaB pathway in inflammation. Cold Spring Harb. Perspect. Biol. 1:a001651. https://doi .org/10.1101/cshperspect.a001651.

Le Provost, F., S. Cassy, H. Hayes, and P. Martin. 2003. Structure and expression of goat GLYCAM1 gene: Lactogenic-dependent expression in ruminant mammary gland and interspecies conservation of the proximal promoter. Gene 313:83-89. https://doi.org/10.1016/ S0378-1119(03)00632-2.

Lehmann, M., O. Wellnitz, and R. M. Bruckmaier. 2013. Concomitant lipopolysaccharide induced transfer of blood-derived components including immunoglobulins into milk. J. Dairy Sci. 96:889-896. https://doi.org/10.3168/jds.2012-5410.

Lemon, P. W., and F. J. Nagle. 1981. Effects of exercise on protein and amino acid metabolism. Med. Sci. Sports Exerc. 13:141-149.

Li, N., R. Richoux, M. Boutinaud, P. Martin, and V. Gagnaire. 2014 Role of somatic cells on dairy processes and products: A review. Dairy Sci. Technol. 94:517-538. https://doi.org/10.1007/s13594 -014-0176-3.

Liu, Y., J. Liao, T. Ku, X. Li, and A. M. Sheppard. 2018. Assessment of milk quality using novel mutations of B2M gene in bovine DNA from milk. CYTA J. Food 16:281-286. https://doi.org/10.1080/ 19476337.2017.1394367.

López-Flores, I., J. Peragón, R. Valderrama, F. J. Esteban, F. Luque, M. A. Peinado, F. Aranda, J. A. Lupiáñez, and J. B. Barroso. 2006. Downregulation in the expression of the serine dehydratase in the rat liver during chronic metabolic acidosis. Am. J. Physiol. Regul. Integr. Comp. Physiol. 291:R1295-R1302. https://doi.org/ 10.1152/ajpregu.00095.2006.

Lund, M. S., B. Guldbrandtsen, A. J. Buitenhuis, B. Thomsen, and C. Bendixen. 2008. Detection of quantitative trait loci in Danish Holstein cattle affecting clinical mastitis, somatic cell score, udder conformation traits and assessment of associated effects on milk yield. J. Dairy Sci. 91:4028-4036. https://doi.org/10.3168/ jds.2007-0290.

Martin, P., H. W. Barkema, L. F. Brito, S. G. Narayana, and F Miglior. 2018. Symposium review: Novel strategies to genetically improve mastitis resistance in dairy cattle. J. Dairy Sci. 101:27242736. https://doi.org/10.3168/jds.2017-13554.

Miles, C. M., and M. Wayne. 2008. Quantitative trait locus (QTL) analysis. Nature Education 1:208. https://www.nature.com/ scitable/topicpage/quantitative-trait-locus-qtl-analysis-53904.

Mortazavi, A., B. A. Williams, K. McCue, L. Schaeffer, and B. Wold. 2008. Mapping and quantifying mammalian transcriptomes by 
RNASeq. Nat. Methods 5:621-628. https://doi.org/10.1038/ nmeth.1226.

Nielsen, B. H., S. Iacobsen, P. H. Andersen, T. A. Niewold, and P. M. H. Heegard. 2004. Acute phase protein concentrations in serum and milk from healthy cows, cows with clinical mastitis and cows with extramammary inflammatory conditions. Vet. Rec. 154:361365. https://doi.org/10.1136/vr.154.12.361.

Paape, M. J., W. P. Wergin, A. J. Guidry, and R. E. Pearson. 1979. Leukocytes - second line of defense against invading mastitis pathogens. J. Dairy Sci. 62:135-153.

Pham, C. T. 2006. Neutrophil serine proteases: Specific regulators of inflammation. Nat. Rev. Immunol. 6:541-550. https://doi.org/10 $.1038 /$ nri1841.

Quinlan, A. R., and I. M. Hall. 2010. BEDTools: A flexible suite of utilities for comparing genomic features. Bioinformatics 26:841842. https://doi.org/10.1093/bioinformatics/btq033.

Roginski, H. 2003. Encyclopedia of Dairy Sciences. Academic Press, London, UK.

Rupp, R., A. Hernandez, and B. A. Mallard. 2007. Association of Bovine Leukocyte Antigen (BoLA) DRB3.2 with immune response, mastitis, and production and type traits in Canadian Holsteins. J. Dairy Sci. 90:1029-1038. https://doi.org/10.3168/jds.S0022 -0302(07)71589-8.

Sanchez, J., F. Markham, I. Dohoo, J. Sheppard, G. Keefe, and K. Lesliec. 2004. Milk antibodies against Ostertagia ostertagi: Relationships with milk IgG and production parameters in lactating dairy cattle. Vet. Parasitol. 120:319-330. https://doi.org/10.1016/ j.vetpar.2004.01.010.

Santman-Berends, I. M., R. G. Olde Riekerink, O. C. Sampimon, G. van Schaik, and T. J. Lam. 2012. Incidence of subclinical mastitis in Dutch dairy heifers in the first 100 days in lactation and associated risk factors. J. Dairy Sci. 95:2476-2484. https://doi.org/10 .3168/jds.2011-4766.

Stelwagen, K., and K. Singh. 2014. The role of tight junctions in mammary gland function. J. Mammary Gland Biol. Neoplasia 19:131138. https://doi.org/10.1007/s10911-013-9309-1.

$\mathrm{Su}, \mathrm{H}$., N. Na, X. Zhang, and Y. Zhao. 2017. The biological function and significance of CD74 in immune diseases. Inflamm. Res. 66:209-216. https://doi.org/10.1007/s00011-016-0995-1.

Szklarczyk, D., J. H. Morris, H. Cook, M. Kuhn, S. Wyder, M. Simonovic, A. Santos, N. T. Doncheva, A. Roth, P. Bork, L. J. Jensen, and C. von Mering. 2017. The STRING database in 2017: Qualitycontrolled protein-protein association networks, made broadly accessible. Nucleic Acids Res. 45(D1):D362-D368. https://doi.org/ 10.1093/nar/gkw937.

Tak, P. P., and G. S. Firestein. 2001. NF-кB: A key role in inflammatory disease. J. Clin. Invest. 107:7-11.

Tao, W., and B. Mallard. 2007. Differentially expressed genes associated with Staphylococcus aureus mastitis of Canadian Holstein cows. Vet. Immunol. Immunopathol. 120:201-211. https://doi.org/ 10.1016/j.vetimm.2007.06.019.

Thomas, P. D., M. J. Campbell, A. Kejariwal, H. Mi, B. Karlak, R. Daverman, K. Diemer, A. Muruganujan, and A. Narechania. 2003. PANTHER: A library of protein families and subfamilies indexed by function. Genome Res. 13:2129-2141. https://doi.org/10.1101/ gr.772403. van Altena, S. E. C., B. de Klerk, K. A. Hettinga, R. J. J. van Neerven, S. Boeren, H. F. J. Savelkoul, and E. J. Tijhaar. 2016. A proteomics-based identification of putative biomarkers for disease in bovine milk. Vet. Immunol. Immunopathol. 174:11-18. https:// doi.org/10.1016/j.vetimm.2016.04.005.

Vandre, R. K., G. R. Gowane, A. K. Sharma, and S. S. Tomar. 2014. Immune responsive role of $\mathrm{MHC}$ class II DQA1 gene in livestock. Livest. Res. Int. 2:1-7.

Whale, T. A., T. K. Beskorwayne, L. A. Babiuk, and P. J. Griebel 2006. Bovine polymorphonuclear cells passively acquire membrane lipids and integral membrane proteins from apoptotic and necrotic cells. J. Leukoc. Biol. 79:1226-1233. https://doi.org/10.1189/jlb .0505282 .

Wickramasinghe, S., A. Cánovas, G. Rincón, and J. F. Medrano. 2014. RNA-Sequencing: A tool to explore new frontiers in animal genetics. Livest. Sci. 166:206-216. https://doi.org/10.1016/j.livsci.2014 .06 .015 .

Wickramasinghe, S., G. Rincon, A. Islas-Trejo, and J. F. Medrano. 2012. Transcriptional profiling of bovine milk using RNA sequencing. BMC Genomics 13:45-58. https://doi.org/10.1186/1471-2164 $-13-45$

Woof, J. M., and D. R. Burton. 2004. Human antibody-Fc receptor interactions illuminated by crystal structures. Nat. Rev. Immunol. 4:89-99. https://doi.org/10.1038/nri1266.

Yang, H., W. Zhang, H. Pan, H. G. Feldser, E. Lainez, C. Miller, S. Leung, H. Zhao, S. Sweitzer, T. Considine, T. Riera, V. Suri, B. White, J. L. Ellis, G. P. Vlasuk, and C. Loh. 2012. SIRT1 activators suppress inflammatory responses through promotion of p65 deacetylation and inhibition of NF-kB activity. PLoS One 7:e46364. https://doi.org/10.1371/journal.pone.0046364.

Yang, Y., W. Shen, X. Zhao, H. Zhao, D. Huang, and G. Cheng. 2014. Proteomics and pathway analysis of N-glycosylated mammary gland proteins in response to Escherichia coli mastitis in cattle. Vet. J. 200:420-425. https://doi.org/10.1016/j.tvjl.2014.03.026.

Zhang, J., D. Dominguez-Solam, S. Hussein, J. E. Lee, A. B. Holmes, M. Bansal, S. Vlasevska, T. Mo, H. Tang, K. Basso, K. Ge, R. Dalla-Favera, and L. Pasqualucci. 2015. Disruption of KMT2D perturbs germinal center B cell development and promotes lymphomagenesis. Nat. Med. 21:1190-1198. https://doi.org/10.1038/ nm.3940.

Zhang, J. M., and J. An. 2007. Cytokines, inflammation and pain. Int. Anesthesiol. Clin. 45:27-37. https://doi.org/10.1097/AIA $.0 \mathrm{~b} 013 \mathrm{e} 318034194 \mathrm{e}$.

Zhao, S., Y. Guo, and Y. Shyr. 2012a. KEGGprofile: An annotation and visualization package for multi-types and multi-groups expression data in KEGG pathway. $\mathrm{R}$ package version $1(1)$.

Zhao, Q., Y. Qian, R. Li, B. Tan, H. Han, M. Liu, and B. Du. 2012b. Norcantharidin facilitates LPS-mediated immune responses by upregulation of AKT/NF-kB signaling in macrophages. PLoS One 7:e44956. https://doi.org/10.1371/journal.pone.0044956.

Zidi, A., E. Casas, M. Amills, J. Jordana, J. Carrizosa, B. Urrutia, and J. M. Serradilla. 2014. Genetic variation at the caprine lactablbumin alpha (LALBA) gene and its association with milk lactose concentration. Anim. Genet. 45:612-613. https://doi.org/10.1111/ age.12152. 